\title{
A Psicologia na Promoção da Saúde do Estudante Universitário
}

\section{Psychology in the Promotion of University Student Health}

\author{
Aparecida Beatriz de Oliveira', Silvia Maria Cintra da Silva² \\ 'Autora para correspondência. Universidade Federal do Triângulo Mineiro. Uberaba, Minas Gerais, Brasil. \\ ORCID: 0000-0002-0907-5717. aparecidabeatriz@yahoo.com.br \\ ${ }^{2}$ Universidade Federal de Uberlândia. Uberlândia, Minas Gerais, Brasil. OCIRD: 0000-0003-0834-5671. silvia@ufu.br
}

\begin{abstract}
RESUMO I A saúde mental de estudantes universitários tem sido tema de muitas pesquisas no país e motivado importantes discussões a partir de perspectivas sociais, econômicas, políticas e pedagógicas, entre outras. Estudos têm demonstrado a vulnerabilidade de saúde dos estudantes, tornando relevante a investigação de intervenções do psicólogo diante dessa problemática. O presente estudo teve como objetivo identificar e analisar práticas desenvolvidas por psicólogos na Assistência Estudantil de universidades públicas federais mineiras, utilizando os pressupostos teórico-metodológicos da Psicologia Escolar Crítica. A pesquisa, de abordagem qualitativa, foi desenvolvida com a participação de 19 psicólogos, que responderam a um questionário. Foram analisadas respostas concernentes ao perfil dos participantes, à prática profissional e às percepções dos psicólogos acerca dela, envolvendo composição dos serviços, modalidades de atuação, desafios e dificuldades com estratégias de enfrentamento e superação; mudanças necessárias; o papel do psicólogo na Assistência Estudantil e compreensão da contribuição de sua atuação para a Educação. Verificou-se a existência de ações de promoção da saúde do estudante e presença da interface da Psicologia com a Educação e a Saúde tanto na formação quanto na atuação dos profissionais.
\end{abstract}

PALAVRAS-CHAVE: Psicologia escolar. Estudantes universitários. Ensino superior. Promoção da saúde

\begin{abstract}
The mental health of university students has been the subject of much research in the country and motivated important discussions from social, economic, political and pedagogical perspectives, among others. Studies have demonstrated the health vulnerability of the students, making relevant the investigation of interventions of the psychologist in front of this problematic. The present study aimed to identify and analyze practices developed by psychologists in the Student Assistance of federal public universities in Minas Gerais, using the theoretical and methodological assumptions of Critical School Psychology. The qualitative research was developed with the participation of 19 psychologists, who answered a questionnaire. Responses concerning the profile $\circ$ the participants, the professional practice and the perceptions of the psychologists about it, were analyzed, involving professional composition of services, modalities of action, challenges and difficulties with strategies of coping and overcoming; necessary changes; role of the psychologist in student assistance and understanding of the contribution of his / her performance to Education. It was verified the existence of actions to promote the student's health and the presence of the interface of Psychology with Education and Health both in the training and in the performance of the professionals.
\end{abstract}

KEYWORDS: School psychology. University students. Higher education. Health promotion 


\section{Introdução}

A saúde mental de estudantes universitários tem sido tema de muitas pesquisas no país e motivado importantes discussões a partir de diferentes perspectivas: sociais, econômicas, políticas e pedagógicas, entre outras. $O$ processo de democratização da educação superior, que vem ocorrendo nas últimas décadas, proporciona uma nova configuração de universidade, mais representativa da sociedade em que está inserida e mais correspondente aos diversos problemas por ela enfrentados. Com o maior acesso de jovens ao ensino superior, o que pode ser verificado pelo aumento significativo no número de matrículas (entre 2003 e 2013 o crescimento foi de $76,4 \%$, segundo o Inep, 2014), mais demandas também chegam à Universidade, tanto no sentido da permanência como da conclusão do curso com qualidade.

Diversos estudos, em diferentes linhas investigativas e perspectivas epistemológicas, têm demonstrado a vulnerabilidade de saúde dos estudantes universitários (Alves, 2014; Cerchiari, Caetano \& Faccenda, 2005; Guimarães, 2014; Souza, 2017).

Recente pesquisa realizada com 384 estudantes de graduação de uma universidade federal mineira demonstrou a presença de sofrimento psíquico neste público, indicando sentimento de solidão em $47 \%$, sintomas depressivos em $59,2 \%$, ansiedade em $70,4 \%$ e $78,1 \%$ apresentaram estresse, sendo $37,2 \%$ já em nível de exaustão. $O$ estudo também apontou relação entre níveis de sintomas ansiosos, depressivos e estressores junto ao sentimento de solidão, sendo que a percepção de suporte social (14,2\% baixa, $69,3 \%$ média e $16,4 \%$ alta) apresentou-se como um possível fator de proteção quanto ao agravo desses sintomas (Souza, 2017).

Uma pesquisa sobre o perfil socioeconômico e cultural dos estudantes de graduação de instituições federais de ensino superior brasileiras, realizada em 2014 , mostrou que $79,8 \%$ desses estudantes relataram ter vivenciado dificuldades emocionais nos últimos doze meses que interferiram em sua vida acadêmica. Dentre essas dificuldades, a mais citada foi ansiedade $(58,36 \%)$, seguida por desânimo e falta de vontade de fazer as coisas $(44,72 \%)$, insônia ou alterações significativas do sono $(32,67 \%)$, sensação de desamparo, desespero e desesperança $(22,55 \%)$ e $21,29 \%$ indicaram sentimento de solidão (Associação Nacional dos Dirigentes das Instituições Federais de Ensino Superior [Andifes], 2016). Em 2003/2004 e em 2010/2011 foi desenvolvida a mesma pesquisa e a porcentagem de estudantes que afirmou enfrentar problemas emocionais com prejuízos acadêmicos foi de $36,9 \%$ na primeira (Andifes, 2004) e 47,7\% na segunda (Andifes, 2011 ). Apesar de a porcentagem ter mais do que duplicado de 2003 para 2014, a última pesquisa demonstra que mais de $60 \%$ nunca procuraram por atendimento psicológico (Andifes, 2016).

Os resultados desses diversos estudos acerca das condições de saúde dos estudantes mostram a relevância de programas destinados à atenção à saúde desse público, com a finalidade de prevenção e promoção da saúde no contexto universitário.

Em Instituições de Ensino Superior (IES), tanto públicas quanto privadas, existem serviços voltados para o atendimento ao público estudantil. Após a instituição do Sistema Nacional de Avaliação da Educação Superior (SINAES), em 2004, houve um estímulo à criação de tais serviços. O SINAES possui o objetivo de assegurar o processo nacional de avaliação das instituições de educação superior, dos cursos de graduação e do desempenho acadêmico de seus estudantes. Em seu artigo $3^{\circ}$, determina que a avaliação das IES terá por objetivo identificar o seu perfil e o significado de sua atuação, por meio de suas atividades, cursos, programas, projetos e setores, considerando dez diferentes dimensões institucionais, dentre as quais estão, obrigatoriamente, as políticas de atendimento ao estudante (Lei 10.861, de 14 de abril de 2004, 2004).

Em relação especificamente às Instituições Federais de Ensino Superior (IFES), em 2007 foi criado - Programa de Apoio a Planos de Reestruturação e Expansão das Universidades Federais (Reuni), por meio do Decreto n. 6. 096, de 24 de abril de 2007 (2007). A quinta diretriz do Reuni também se refere à ampliação de políticas de inclusão e Assistência Estudantil e serviu como estímulo ao investimento das instituições nessa área.

A política de Assistência Estudantil das IFES é norteada pelo Programa Nacional de Assistência Es- 
tudantil (PNAES). Em agosto de 2007, a ANDIFES lançou o Plano Nacional de Assistência Estudantil (PNAES), baseando-se em dados de pesquisas sobre o perfil dos estudantes dos cursos de graduação das IFES. Em 2010, o PNAES foi consolidado como programa de estado, instituído no âmbito do Ministério da Educação (MEC) e convertido em Programa Nacional de Assistência Estudantil, mantendo-se a mesma sigla (ANDIFES, 2011).

O PNAES tem como objetivo ampliar as condições de permanência dos estudantes na educação pública superior federal e define dez áreas em que devem ser desenvolvidas as ações da Assistência Estudantil: moradia estudantil; alimentação; transporte; atenção à saúde; inclusão digital; cultura; esporte; creche; apoio pedagógico; acesso, participação e aprendizagem de estudantes com deficiência, transtornos globais de desenvolvimento e altas habilidades e superdotação (Decreto $n^{\circ} 7234$, de 19 de julho de $2010,2010)$. Para que a abordagem de todas as áreas estratégicas seja ampla e eficiente é imperioso o trabalho conjugado do órgão que trata dos assuntos estudantis com outros órgãos da universidade ligados ao ensino, pesquisa, extensão e cultura, bem como parcerias com órgãos públicos federais, estaduais e municipais e entidades da sociedade civil.

Diante do cenário acima apresentado, torna-se fundamental a investigação das ações dos profissionais atuantes na Assistência Estudantil em relação à multiplicidade das inúmeras questões apresentadas pelos estudantes que comprometem sua saúde e qualidade de vida, sua permanência no ensino superior e seu sucesso acadêmico. Na Assistência Estudantil, o psicólogo constitui um dos profissionais importantes no desenvolvimento de ações que podem promover a permanência e o sucesso acadêmico dos universitários. Essa constitui uma das relevâncias do presente estudo que teve como objetivo identificar e analisar práticas desenvolvidas por psicólogos na Assistência Estudantil de universidades públicas federais mineiras. Na literatura acadêmica são encontradas diversas pesquisas acerca das condições de saúde e de outras problemáticas referentes aos estudantes universitários, mas há poucas relativas à atuação do psicólogo frente a elas.

Além disso, o estudo de práticas concretas do psicólogo na Assistência Estudantil permite revelar ele- mentos importantes para aprofundar a compreensão dos limites e possibilidades dessa prática, das transformações e superações necessárias, bem como pode contribuir para difundir e valorizar os avanços, enfrentamentos e conquistas já alcançados nessa área. Outro ponto a ser igualmente considerado é o impacto direto do trabalho do psicólogo junto aos estudantes universitários, no sentido do cuidado com a permanência e a conclusão do curso com qualidade.

A pesquisa foi embasada na Psicologia Escolar Crítica, perspectiva teórica que defende que a atuação do psicólogo em contextos educativos deve considerar o seu compromisso na colaboração por uma educação de qualidade social e na busca da ruptura da visão adaptacionista da Psicologia (Souza, 2010). Conforme afirma Guzzo (2001), refletir sobre questões da Educação, Desenvolvimento, Saúde e Direitos Humanos tem se apresentado como um desafio constante e presente e vem fazendo parte do discurso de inúmeras pessoas nessas áreas, inclusive de profissionais da Psicologia Escolar.

\section{Método}

Este trabalho teve como objetivo identificar e analisar as práticas desenvolvidas por psicólogos na Assistência Estudantil de universidades públicas federais mineiras. Neste estudo foram enfocados, especialmente, elementos tangentes à promoção da saúde e qualidade de vida dos estudantes universitários.

A pesquisa, de abordagem qualitativa, foi desenvolvida com a participação de 19 psicólogos atuantes em setores responsáveis pela Assistência Estudantil das universidades federais mineiras, correspondendo a $43,18 \%$ do total de 44 profissionais localizados. Todos os psicólogos que atuavam nestes setores nas onze universidades federais existentes em Minas Gerais foram convidados a participar por meio de um convite on-line, com link para um questionário também neste formato. $O$ estado de Minas Gerais possui o maior número de universidades públicas federais do Brasil, a saber: Universidade Federal de Alfenas (UNIFAL); Universidade Federal de Itajubá (UNIFEI); Universidade Federal de Juiz de Fora 
(UFJF); Universidade Federal de Lavras (UFLA); Universidade Federal de Minas Gerais (UFMG); Universidade Federal de Ouro Preto (UFOP); Universidade Federal de São João Del Rei (UFSJ); Universidade Federal do Triângulo Mineiro (UFTM); Universidade Federal de Uberlândia (UFU);Universidade Federal de Viçosa (UFV); e Universidade Federal dos Vales do Jequitinhonha e Mucuri (UFVJM). O questionário foi escolhido como instrumento de pesquisa devido a fatores como o grande número de questões relacionadas ao objetivo do estudo e necessárias à consecução deste, a necessidade de acesso aos profissionais, uma vez que os sujeitos pesquisados localizam-se em diferentes municípios mineiros e a possibilidade de ser respondido no momento em que estes estivessem mais disponíveis ou julgassem mais conveniente.

Realizamos um levantamento dos e-mails dos psicólogos, obtidos por meio dos sites institucionais ou por contato telefônico com o setor da instituição, após a aprovação do projeto pelo Comitê de Ética em Pesquisa da Universidade Federal de Uberlândia (CAAE 40961215.3.0000.5152). Enviamos o convite à participação e o Termo de Consentimento Livre e Esclarecido (TCLE) por e-mail. Aqueles profissionais que concordaram em participar nos enviaram o questionário respondido e o TCLE assinado e escaneado.

O questionário foi constituído por questões fechadas, abertas e mistas em conformidade com os objetivos da pesquisa. Neste artigo apresentaremos dados sobre o perfil dos participantes de forma breve, enfocando a análise de questões referentes à prática profissional e às percepções dos psicólogos acerca dela, envolvendo composição dos serviços, modalidades de atuação, desafios e dificuldades com estratégias de enfrentamento e superação; mudanças necessárias; papel do psicólogo na Assistência Estudantil e compreensão da contribuição de sua atuação para a educação.

\section{Resultados e Discussão}

Participaram da pesquisa 19 psicólogos sendo 13 do sexo feminino $(68,42 \%)$ e seis do sexo masculino $(31,58 \%)$. A média de idade no presente estu- do foi de 35 anos, com predomínio na faixa etária de 28 a 43 anos $(84,21 \%)$. Foi possível observar que a maioria não é recém formada, uma vez que $89,47 \%$ concluíram a graduação há mais de cinco anos e a média de tempo de formação entre eles é de aproximadamente dez anos. Também possuem uma bagagem considerável de experiência profissional, tendo em vista que o tempo de experiência está entre cinco e 25 anos.

Anteriormente ao seu ingresso como psicólogo na Assistência Estudantil, os profissionais adquiriram prática em diversas áreas da Psicologia: Clínica, Social, da Saúde, do Trânsito, Hospitalar, Organizacional, Escolar e Educacional e na docência no ensino superior. Todos atuaram em mais de uma área da Psicologia e investiram em cursos de pós-graduação lato e/ou stricto sensu ou em outras modalidades de formação continuada. Os cursos realizados referem-se a diferentes campos da Psicologia e a áreas relacionadas com a saúde, educação ou gestão do trabalho. A maior parte deles relaciona-se com as ações desenvolvidas pelos profissionais na Assistência Estudantil verificadas neste estudo.

A maioria dos psicólogos (89,5\%) está há sete anos na Assistência Estudantil, no máximo. Verificamos que esse tempo corresponde ao período que sucede à instituição do Reuni e ao lançamento do Plano Nacional de Assistência Estudantil, ambos ocorridos em 2007. Por conseguinte, podemos observar que a maioria dos psicólogos entrevistados ingressou na Assistência Estudantil em decorrência do Reuni, - que é constatado também na pesquisa de Moura (2015), realizada com psicólogos atuantes em universidades federais dos Estados do Paraná, Rio Grande do Sul e Santa Catarina. Assim, consideramos que essa política pública teve um importante impacto na presença de psicólogos nesse nível de ensino, embora, segundo o autor, nos editais dos concursos nas supracitadas universidades, não estava clara qual a atuação esperada para esse profissional: "Muitas vezes, a descrição do cargo é generalista e, por vezes, pautada em uma concepção clínica de atendimento." (Moura, 2015, p. 90).

Dessa forma, o perfil de psicólogos desta pesquisa é formado por profissionais que ingressaram recentemente na Assistência Estudantil e, por essa razão, têm muito a construir e a aperfeiçoar em sua prá- 
tica. Em contrapartida, possuem experiência profissional e investem em educação continuada acerca de temas relacionados à sua atuação, demonstrando compromisso, interesse e engajamento em seu trabalho. A formação continuada e o envolvimento com a atividade produtiva são fundamentais para impulsionar o planejamento, elaboração e desenvolvimento de ações mais efetivas e transformadoras mediante os desafios que sua realidade apresenta.

Os Serviços de Assistência Estudantil (SAE) foram criados para atender às necessidades institucionais das universidades em que estão inseridos e o serviço de Psicologia organiza-se de diferentes formas, de maneira que cada universidade apresenta sua especificidade em relação à organização, gestão e desenvolvimento do SAE.

Segundo Mészaros (2006), Marx distingue o trabaIho como manifestação de vida (Lebensäusserung) do trabalho considerado como alienação de vida (Lebensentäusserung). Neste último, trabalha-se para a produção de um meio de vida, mas o trabalho é imposto como uma necessidade externa e não interna. O trabalho como manifestação de vida requer que seja uma atividade correspondente a uma necessidade interior do sujeito. Esses profissionais, ao se envolverem com sua atividade produtiva e ao buscarem mais conhecimentos e saberes que possam colaborar para seu aperfeiçoamento, indicam um comprometimento com a sua atuação, demonstrando que buscam se apropriar de sua prática como manifestação de vida e emancipação humana.

Em relação à composição profissional, foi possível constatar que os psicólogos atuam em equipe constituída por profissionais ligados à área de humanas e/ou de saúde. Analisando as respostas, organizamos a categorização das equipes em cinco subcategorias, de acordo com a área de formação dos profissionais: (a) Psicossocial; (b) Psicossocial e Educacional; (c) Psicossocial e de Saúde; (d) Psicoeducacional; (e) Psicoeducacional e de Saúde.

Cinco dos psicólogos participantes (28\%) compõem uma Equipe Psicossocial. Nela, o assistente social é o único profissional de área diferente que constitui a equipe com o psicólogo. A Equipe Psicossocial e Educacional apresenta-se como predominante entre os participantes $(44 \%)$, sendo composta por psicó- logos, assistentes sociais e pedagogo. A Equipe Psicossocial e de Saúde, que abarca $11 \%$ dos psicólogos participantes, é formada pelo assistente social e por profissionais da área da saúde como médico, psiquiatra, enfermeiro e nutricionista. Somente um participante encaixa-se na Equipe Psicoeducacional (6\%), formada por psicólogos e profissionais da área da educação, como pedagogas e técnicos em assuntos educacionais. A Equipe Psicoeducacional e de Saúde (1 $1 \%)$, além do psicólogo, é formada por profissionais da educação como pedagoga e técnicos em assuntos educacionais e pelos da área da saúde como médico, enfermeiro, nutricionista, fisioterapeuta e dentista.

Considerando a complexidade das questões que envolvem o estudante na educação superior, faz-se importante constatar a existência da composição de equipes multidisciplinares na Assistência Estudantil. Conforme afirma Contini (2000), a promoção da saúde e a melhor compreensão da complexidade do fenômeno humano somente são possíveis por meio do diálogo com outras áreas, tanto na prática profissional quanto na produção de novos saberes. Sampaio (2010) defende que o psicólogo que atua na educação superior precisa fazer uma interlocução com outros campos do saber com vistas à compreensão mais ampla do universo com o qual se propõe a trabalhar. Para tal, de acordo com a autora, é tarefa urgente o desenvolvimento do trabalho em equipes multidisciplinares. Percebemos que a composição em equipes é um dos fatores constitutivos da assistência estudantil, nas quais o psicólogo está inserido e tem a sua prática contextualizada.

Em relação à organização do trabalho nas equipes, constatamos que em todas há espaços formais e informais para discussão de práticas com os outros profissionais. As reuniões de equipe são organizadas de forma mensal, quinzenal ou semanal, dependendo da realidade institucional. Naquelas que envolvem profissionais de diferentes áreas, podem ocorrer discussão de casos que envolvem mais de uma área, proposição de projetos e a organização de ações conjuntas e programas multidisciplinares. Também podem acontecer reuniões com objetivo mais amplo, como o de tratar da reformulação do regulamento sobre a política de Assistência Estudantil da universidade. Neste último caso, envolvem servidores de todos os setores da Assistência Estudan- 
til. Além das reuniões formais, há espaços informais para discussão de práticas cotidianas para que os profissionais das áreas envolvidas se auxiliem mutuamente. Entendemos que essas reuniões são fundamentais e imprescindíveis para a organização e o desenvolvimento do trabalho em equipe, uma vez que constituem espaços concretos e democráticos de diálogo, cooperação, envolvimento e interação entre os profissionais.

Na pesquisa foram identificadas modalidades de atuação tanto de enfoque individual, quanto de enfoque grupal e/ou coletivo. Entre as de enfoque individual estão: orientação psicológica $(78 \%)$; plantão psicológico (67\%); psicoterapia individual $(56 \%)$; acolhimento $(17 \%)$; orientação psicopedagógica (11\%); orientação profissional (11\%); acompanhamento psicopedagógico (6\%) e intervenção em Psicologia Escolar e Educacional (6\%). As modalidades de enfoque grupal e/ou coletivo apontadas são: projetos/programas (44\%); grupo temático $(33 \%)$; grupo terapêutico e de apoio a estudantes migrantes $(22 \%)$; psicoterapia grupal (11\%); palestras, seminários e minicursos $(11 \%)$; orientação grupal de enfoque profissional e de carreira $(6 \%)$; orientações grupais com diferentes enfoques $(6 \%)$; oficinas terapêuticas (6\%) e oficinas temáticas (6\%).

As modalidades de atendimento individual ao estudante foram predominantes. Martínez (2009) classifica-as como práticas tradicionais, associadas à dimensão psicoeducativa do contexto educacional. Percebemos que essas práticas clínicas encontram-se articuladas com o contexto educativo e institucional, tendo em vista que o seu objetivo é proporcionar suporte psicossocial para que o estudante consiga permanecer e concluir seu curso com sucesso. Dessa forma, diferem-se de uma perspectiva patologizante, descontextualizada e que culpabiliza o estudante, amplamente criticada por autores da Psicologia Escolar Crítica, como Facci e Silva (2014). As modalidades de atendimento individual são utilizadas como espaço de escuta das diferentes questões que envolvem a vida do estudante, nos aspectos emocionais, educacionais, sociais, econômicos, de moradia e outros que interferem de alguma forma no desempenho acadêmico e podem comprometer a permanência do estudante no ensino superior. Essas modalidades constituem um espaço de promoção de saúde em nível individual, uma vez que, em equipe e em articulação com outros setores da universidade, é possível fazer intervenções que considerem o contexto de vida do sujeito e seu processo educativo. Além disso, elas são utilizadas por alguns profissionais como meio de levantar demandas para elaboração e execução de programas/projetos e de modalidades de enfoque grupal ou coletivo, de maneira a ampliar sua prática e possibilitar uma intervenção mais articulada com a instituição.

Acreditamos, entretanto, ser necessário pensar em estratégias de se trabalhar de forma coletiva e interdisciplinar os problemas que chegam por meio de solicitações de atendimento individual, o que requer uma mudança de visão e postura diante do estudante e de seu processo educativo, abandonando a perspectiva individualizante e fracionada dos dilemas apresentados, concebendo as questões apresentadas como componentes de um vasto processo educacional, sociopolítico, intersubjetivo e inter-relacional, a partir do qual o psicólogo escolar deve priorizar sua intervenção. A superação dessa perspectiva individualizante dos problemas é também defendida por autores da Psicologia Escolar Crítica (Facci \& Silva, 2014; Marinho-Araúijo, 2009; Martínez, 2009; Meira, 2007; Meira \& Antunes, 2003; Souza, 2010).

Conforme definição de Martínez (2009), formas de atuação "tradicionais" são aquelas ligadas à dimensão psicoeducativa e definidas a partir dos problemas concretos relacionados ao desenvolvimento e aprendizagem dos estudantes que demandam solução e para os quais a intervenção do psicólogo constitui uma resposta. Podem ser classificadas como tradicionais todas as modalidades desenvolvidas de enfoque individual, a orientação a pais, familiares e professores, a psicoterapia grupal, a orientação profissional e a elaboração e coordenação de grupos específicos com finalidade educativa e preventiva. As formas de atuação "emergentes", de acordo com a autora, estão associadas à dimensão psicossocial, considerando a escola "não apenas como um lugar onde uns ensinam e outros aprendem, mas como um espaço social sui generis no qual as pessoas convivem e atuam" (Martínez, 2009, p. 172). Ao utilizar as modalidades de atendimento clínico como meio de diagnóstico e análise da subjetividade social na universidade e, a partir dessa análise, delinear ações a fim de otimizar o proces- 
so educativo, os psicólogos estão, em conformidade com a autora, atuando de forma "emergente".

Além disso, verificou-se o desenvolvimento de diversas atividades que objetivam a promoção da saúde e o desenvolvimento integral do universitário, que constituem formas de atuação "emergentes" (Martínez, 2009) e englobam ações de interface da Psicologia com a Saúde e com a Educação. Entre essas atividades estão programas e projetos voltados ao debate e produção de conhecimentos acerca da saúde do estudante e de sua vida acadêmica; projetos de interlocução com coordenadores de cursos; de intervenção em sala de aula com enfoque psicopedagógico, psicossocial ou de saúde; ações de promoção e prevenção de saúde nos alojamentos; projetos direcionados ao desenvolvimento integral do estudante em forma de grupos ou oficinas, que abordam temas de conteúdo psicológico, como desenvolvimento interpessoal, assertividade, enfrentamento de timidez e fobias sociais. Tais programas e projetos, geralmente, são desenvolvidos em equipe e articulam-se com o corpo docente e/ou outros setores da universidade. Também foi possível constatar a participação dos psicólogos em comissões e grupos de trabalho institucionais.

Os psicólogos apontaram diversas dificuldades e desafios que encontram em sua prática, entre os quais estão: a) constantes mudanças nas políticas educacionais; b) necessidade de definição do papel do psicólogo na Assistência Estudantil; c) desenvolvimento de pouca ou nenhuma prática interdisciplinar; d) grande demanda para atendimento clínico psicoterápico e pouco fomento e baixa adesão às ações grupais, e) diversidade de demandas recebidas.

As mudanças decorrentes das políticas de democratização da Educação Superior também têm trazido diversas questões de ordem social, econômica, familiar, relacional, cultural e regional, de difícil e complexa abordagem. Com a democratização do acesso ao Ensino Superior, a sociedade brasileira, em seus diferentes aspectos étnicos, culturais, regionais, sociais e econômicos, está melhor representada neste âmbito educacional. Dessa forma, as problemáticas e questões, existentes na sociedade em geral e também na universidade, estão sendo intensificadas e a instituição precisa aprender a lidar com demandas que antes, por seu caráter excludente e seletivo, não existiam ou ocorriam em número insignificante. É crescente a entrada de estudantes de origem popular, afrodescendentes, com deficiências, bem como de estudantes migrantes, provenientes de diferentes regiões brasileiras, optando por morar bem distantes da família, estimulados pelos resultados do Sistema de Seleção Unificada (Sisu), o que se soma ao desejo de estudar em uma universidade pública federal. Todos esses estudantes compõem um novo cenário na universidade pública, requisitando tanto o desenvolvimento de estudos que permitam conhecer melhor essa clientela, quanto a definição de políticas e medidas pedagógicas e sociais que possibilitem a permanência, a formação integral e a conclusão do curso desses novos sujeitos da educação.

É em meio a essa diversidade e complexidade que o psicólogo, juntamente com outros profissionais da Assistência Estudantil, é convidado a atuar. Assim, faz-se necessária uma definição de seu papel na Assistência Estudantil, pois o que o profissional acredita ser $\circ$ seu papel configura as modalidades, 0 contexto e a amplitude de sua atuação, bem como seu compromisso com as transformações necessárias à Educação (Souza, 2010).

Os psicólogos participantes apontaram a necessidade e dificuldade de se desenvolver ações interdisciplinares, as quais poderiam ser mais efetivas na promoção da saúde do estudante. Tal fato ratifica a importância de se garantir as reuniões de equipe como um espaço de discussão de práticas e elaboração de intervenções conjuntas, pois é no encontro com o outro que as ideias, as soluções e as estratégias de enfrentamento surgem. Contini (2000) afirma que a tarefa do trabalho interdisciplinar constitui um desafio fundamental para uma perspectiva de promoção da saúde. Entretanto, se esse desafio for transformado em compromisso e ação na atuação do psicólogo na Educação poderá contribuir na superação da exclusão e do fracasso escolar.

Em relação à diversidade de demandas surgidas para o psicólogo na Assistência Estudantil, procuramos investigar quais são consideradas mais desafiantes na abordagem, tratamento e acompanhamento. Ao analisar as respostas, percebemos que, de forma geral, as mais desafiadoras são aquelas que extrapolam o campo técnico do psicólogo, exi- 
gindo a articulação com outros setores, dentro e fora da universidade. A maioria dos psicólogos (65\%) apontou demandas relativas a questões institucionais e pedagógicas, tais como: a) problemas na relação aluno-professor, como transgressão de normas acadêmicas por parte dos professores, autoritarismo em sala de aula, abuso de poder no processo avaliativo e assédio moral; b) métodos de ensino e práticas educativas perversas e excludentes; c) disciplinas tradicionalmente reprovadoras; d) modos de avaliação tradicionais; e e) mudanças decorrentes das políticas de democratização da Educação Superior. As demandas de saúde mental também foram mencionadas como de difícil abordagem por $53 \%$ dos participantes e relacionam-se a quadros graves e crônicos de adoecimento psíquico; quadros de crises ou surtos; queixas relacionadas a uso e abuso de drogas, a situações de violência sexual ou moral; à dificuldade de adaptação e a relações familiares conflitantes.

Peres, Santos e Coelho $(2003 ;$ 2004) desenvolveram estudos sobre um programa de atendimento psicológico voltado aos estudantes da Universidade Estadual Paulista (UNESP) e agruparam as queixas iniciais apresentadas por eles em três categorias: dificuldades psicológicas circunstanciais (tais como problemas de convívio com companheiros de moradia, ansiedade e estresse em virtude das provas e atividades acadêmicas); dificuldades psicológicas moderadas (como dificuldades de adaptação à cidade e de distanciar-se da família e de amigos da cidade de origem); e dificuldades psicológicas severas (como depressão, alcoolismo, drogadição e tentativas de suicídio). $O$ estudo de Cerchiari, Caetano e Faccenda (2005) sobre um Centro de Atendimento Psicológico para a Comunidade Acadêmica da Universidade Estadual do Mato Grosso do Sul (CAP/UEMS) também indicou resultados semelhantes em relação às queixas. Os autores compilaram as demandas em dois subgrupos: dificuldades psicológicas não psiquiátricas, relacionadas a dificuldades circunstanciais, interpessoais e cotidianas, e diagnósticos classificados de acordo com o Manual Diagnóstico e Estatístico de Transtornos Mentais (DSM IV), tais como transtornos de ansiedade generalizada, transtornos por uso de substâncias psicoativas, transtornos alimentares, transtorno do pânico e outros.
Além das demandas relativas à saúde mental do estudante, também apontadas nas pesquisas de $\mathrm{Pe}$ res, Santos e Coelho $(2003 ; 2004)$ e de Cerchiari, Caetano e Faccenda (2005), este estudo apresenta demandas concernentes a problemas de ordem institucional e pedagógica, exigindo um repensar de práticas educativas e de relações interpessoais, tendo em vista que tais práticas e relações provocam sofrimento e adoecimento psíquico e não são cabíveis em uma instituição educativa que se propõe a propiciar uma educação de qualidade.

Assim, cabe indagar: como o psicólogo escolar pode contribuir com o Ensino Superior? Para Marinho-Araújo (2009), este profissional pode colaborar com a formação dos sujeitos para a vida social no aprofundamento e fortalecimento de sua autonomia e emancipação, por meio de sua relação com o conhecimento, com a crítica e reflexão, e com o exercício político da participação social. Além disso, nas diversas atividades acima elencadas, estão envolvidos outros atores do processo educacional, que não apenas os estudantes: docentes, coordenadores de curso e técnicos administrativos. Todos eles compõem e se constituem na universidade, ao mesmo tempo em que a constituem com suas práticas, posturas e ações. E é justamente por isso que precisam ser convidados ao trabalho em parceria com o psicólogo, pois muitas questões apresentadas por estudantes advêm das relações com docentes, com a organização curricular, metodologias de ensino, propostas avaliativas e outras, que podem começar na sala de aula e se espraiar para as demais esferas da vida estudantil, como os próprios participantes da pesquisa relataram.

Nessa perspectiva, Marinho-Araújo (2009) apresenta três dimensões de intervenção institucional da Psicologia Escolar na Educação Superior considerando intervenções mais amplas, balizadas por ações coletivas e relacionais: (a) Gestão de políticas, programas e processos educacionais nas instituições de Ensino Superior; (b) Propostas pedagógicas e funcionamento de cursos; e (c) Perfil do estudante. Segundo a autora, essas ações institucionais, coletivas e relacionais constituem o eixo da intervenção institucional contemporânea em Psicologia Escolar nesse âmbito de ensino. 
Diante das inúmeras dificuldades e desafios enfrentados pelos psicólogos em sua atuação, foram apontadas estratégias de enfrentamento e superação para cada uma delas. De forma geral, os profissionais buscam estratégias de superação de tais desafios na capacitação e qualificação permanentes; nas reuniões e trabalhos em equipe; na aproximação e busca de diálogo com profissionais de outros setores; na criação de espaços para sistematizar uma atuação conjunta no acompanhamento e atendimento aos estudantes; na articulação com outros projetos e setores; na apresentação e discussão sobre atuação do profissional de Psicologia na instituição; na troca de experiências e discussão com colegas da mesma instituição ou de outras IFES; na busca por formação continuada em Assistência Estudantil por meio da participação em eventos doFórum Nacional de Pró-Reitores de Assuntos Comunitários e Estudantis (Fonaprace); e na invenção de práticas consideradas relevantes no contexto universitário, devido à inexistência de modelos prontos.

As estratégias mencionadas pelos participantes mostram a necessidade do desenvolvimento de um trabalho articulado com diversos setores da universidade; da criação e manutenção de espaços de discussão de práticas e saberes e de planejamento e elaboração de intervenções interdisciplinares e intersetoriais; e do investimento em educação continuada. Além disso, demonstram também a necessidade de o psicólogo ser ativo e criativo, não esperando que as soluções the cheguem prontas, mas administrando conscientemente as demandas que surgem, buscando alternativas e criando novas formas de ação, numa dinâmica de inventar e reinventar sempre, respaldado pelo coletivo. A imperiosa necessidade da formação continuada (Facci \& Silva, 2014), que pode ser efetuada de diferentes formas e modalidades, como a realização de cursos, participação em eventos, supervisão, partilha de experiências, etc., precisa ser valorizada e legitimada pela IES.

A maioria dos psicólogos $(63,15 \%)$ afirmou que mudaria ou já está mudando algo em sua prática no intuito de melhorar. Algumas mudanças apontadas referem-se às seguintes necessidades: a) melhor sistematização e avaliação da prática; b) busca de auxílio teórico e técnico em relação a algumas demandas atendidas, a demandas grupais e à espe- cificidade da atuação do psicólogo escolar; c) ampliação das modalidades de atuação, no sentido de desenvolver formas cada vez menos individualizadas, que extrapolem o campo da clínica, trabalhem a prevenção e promoção da saúde e envolvam o contexto acadêmico como um todo; e d) desenvolvimento de um trabalho de natureza institucional, de forma a atuar mais próximo aos professores e na formação docente. As respostas referentes às mudanças necessárias demonstram que a maioria dos psicólogos está aberta a realizar transformações em sua prática e que tais modificações estão em consonância com as propostas e pressupostos da Psicologia Escolar Crítica (Facci \& Silva, 2014; Martínez, 2009; Meira \& Antunes, 2003) no sentido de buscar uma atuação mais abrangente e contextualizada.

Verificamos, todavia, a existência de uma indefinição acerca do papel do psicólogo na Assistência Estudantil decorrente da ausência de referências de atuação desses profissionais nesta área. Entretanto, embora não haja uma definição clara desse papel, as respostas da maioria dos psicólogos $(84,21 \%)$ relativas a esta questão indicam a interface da Psicologia com a Educação e a Saúde. Esses psicólogos integram todas as equipes pesquisadas e acreditam que o papel do psicólogo vincula-se ao campo de interação tanto da Psicologia com a Saúde quanto da Psicologia com a Educação. Notamos a presença do uso de termos tais como "promoção e prevenção da saúde"; "qualidade de vida", "atenção à saúde" e "bem estar", "desenvolvimento saudável" relacionados à Saúde, combinados na mesma resposta com palavras relativas à Educação, tais como "condições acadêmicas", "processo de formação e construção de sua vida profissional", "inclusão" e "desenvolvimento" na universidade, "desempenho", "vida acadêmica" ou "vida universitária", "formação acadêmica", "formação profissional", e "processo ensino-aprendizagem".

De acordo com a perspectiva de promoção da saúde defendida por diversos autores (Contini, 2000; Dias, Patias, \& Abaid, 2014; Guzzo, 2001), a saúde é decorrente da relação equilibrada entre os diversos elementos da vida concreta e cotidiana do sujeito, como moradia, trabalho, lazer e educação. Portanto, ela possui uma relação intrínseca com a 
educação, em que ações no âmbito da promoção da saúde interferem significativamente e diretamente no processo educativo.

Os psicólogos participantes acreditam que a contribuição de sua atuação para a Educação se dá por meio de sua participação nas políticas de Assistência Estudantil; de intervenções institucionais e do atendimento ao estudante, em suas diferentes perspectivas: escuta psicológica, projetos desenvolvidos em grupo e da promoção da saúde e qualidade de vida. Na prática, todas essas formas de contribuição relacionam-se entre si e devem ser consideradas em seu conjunto, de maneira a impactar positivamente o sistema educacional.

Em relação a impactar a Educação por meio da ação profissional, Guzzo (2001) aponta ser possível somente por meio de um modelo de intervenção direcionado para a prevenção dos problemas socioemocionais, promoção da saúde psicológica e controle do currículo acadêmico que reduza o problema individual do não aprendizado tornando o espaço educativo um lugar em que os estudantes possam sentir prazer em estudar e aprender e possam tornar-se competentes perante as demandas de sua vida.

\section{Considerações Finais}

O presente estudo possibilitou conhecer a prática dos psicólogos atuantes na Assistência Estudantil de universidades federais mineiras e verificar a existência de ações de promoção da saúde do universitário. A pesquisa constatou que os psicólogos possuem experiência profissional em diversas áreas da Psicologia e buscam formação continuada em temas relativos à interface Psicologia, Saúde e Educação, os quais são referentes à sua atuação na Assistência Estudantil. Esse fato indica interesse e engajamento nas questões que envolvem sua prática e um compromisso ético e político com as questões socioeducacionais e os desafios apresentados por elas. Além disso, os profissionais procuram agir de forma criativa, inventando e reinventando novas ações no contexto institucional, na tentativa de buscar solu- ções mais efetivas para os problemas que surgem. Reconhecem que precisam aperfeiçoar a sua atuação, encontram-se abertos a mudanças apontadas por eles mesmos nesse sentido e relatam estratégias de enfrentamento e superação das dificuldades e desafios.

A interface Psicologia, Saúde e Educação também foi percebida nas modalidades de atuação de âmbito individual, grupal e coletivo, nas concepções acerca do papel do psicólogo na Assistência Estudantil e em suas contribuições para a Educação Superior. A ampliação do desenvolvimento de ações interdisciplinares e de prevenção e promoção da saúde do estudante universitário foi apontada como uma das mudanças necessárias.

O estudo relatado foi pioneiro em relação ao campo e ao público investigado, mas possui limitações, visto que transformações da realidade estão sempre ocorrendo e demandam novas pesquisas. Entretanto, a investigação contribuiu na medida em que trouxe elementos que possibilitaram a discussão sobre as práticas desenvolvidas pelos psicólogos diante das questões apresentadas pelos estudantes que comprometem sua saúde e qualidade de vida, sua permanência no ensino superior e seu sucesso acadêmico. Seria interessante cotejar os resultados com investigações realizadas em outras regiões brasileiras, além do Sul, Sudeste e Distrito Federal, que já foram objeto de trabalhos aqui mencionados.

Entendemos que as ações de Assistência Estudantil no âmbito da promoção da saúde do universitário devem buscar articulação com $\circ$ ensino, a pesquisa e a extensão, com a finalidade de serem mais efetivas e eficazes, uma vez que o grande desafio, tarefa e compromisso de todos os que buscam uma educação de qualidade é construir um espaço educativo promotor de saúde para toda a comunidade acadêmica e $\circ$ psicólogo constitui um profissional fundamental nessa busca e conquista.

\section{Conflitos de interesses}

Nenhum conflito financeiro, legal ou político envolvendo terceiros (governo, empresas e fundações privadas, etc.) foi declarado para nenhum aspecto do trabalho submetido (incluindo mas não limitandose a subvenções e financiamentos, conselho consultivo, desenho de estudo, preparação de manuscrito, análise estatística, etc). 


\section{Referências}

Alves, T. C. T. F. (2014). Depressão e ansiedade entre estudantes da área de saúde. Revista de Medicina, 93(3), 101-105. Recuperado de http://www. revistas.usp.br/revistadc/article/view/103400. doi: 10.11606/issn.1679-9836.v93i3p101-105

Associação Nacional dos Dirigentes das Instituições Federais de Ensino Superior. (2004). Perfil Socioeconômico e Cultural dos Estudantes de Graduação das IFES. Brasília, DF: Autor. Recuperado de http://www.andifes.org.br/ wp-content/files_flutter/Biblioteca_041_Pesquisa_ do_Perfil_Socioeconomico_dos_Estudantes_de_ Graduacao_das_IFES.pdf

Associação Nacional dos Dirigentes das Instituições Federais de Ensino Superior (2011). Perfil Socioeconômico e Cultural dos Estudantes de Graduação das Universidades Federais Brasileiras. Brasília, DF: Autor.

Associação Nacional dos Dirigentes das Instituições Federais de Ensino Superior (2016). IV Pesquisa do Perfil Socioeconômico e Cultural dos Estudantes de Graduação das Instituições Federais de Ensino Superior Brasileiras. Uberlândia, MG: Autor. Recuperado de http://www. andifes.org.br/wp-content/uploads/2017/11/Pesquisa-de-Perfil-dos-Graduanso-das-IFES_2014.pdf

Cerchiari, E. A. N., Caetano, D., \& Faccenda, O. (2005). Utilização do serviço de saúde mental em uma universidade pública. Psicologia Ciência e Profissão, 25(2), 252-265. Recuperado de http://www.scielo. $\mathrm{br} / \mathrm{pdf} / \mathrm{pcp} / \mathrm{v} 25 \mathrm{n} 2 / \mathrm{v} 25 \mathrm{n} 2 \mathrm{a} 08 . \mathrm{pdf}$. doi: $10.1590 /$ S1414-98932005000200008

Contini, M. L. J. (2000). Discutindo o conceito de promoção de saúde no trabalho do psicólogo que atua na educação. Psicologia Ciência e Profissão, 20(2), 46-59. Recuperado de http://www.scielo. $\mathrm{br} /$ scielo.php?script=sci_arttext\&pid=S1 414 $98932000000200008 \& \operatorname{lng}=p t \& t \operatorname{lng}=p t$. doi: $10.1590 / \mathrm{S} 1414-98932000000200008$

Decreto n. 6.096, de 24 de abril de 2007. Institui o Programa de Apoio a Planos de Reestruturação e Expansão das Universidades Federais - REUNI. Recuperado de http://www.planalto.gov.br/ccivil_03/_ato20072010/2007/decreto/d6096.htm

Decreto n. 7.234, de 19 de julho de 2010. Dispõe sobre - Programa Nacional de Assistência Estudantil PNAES. Recuperado de http://www.planalto.gov.br/ ccivil_03/_Ato2007-2010/2010/Decreto/D7234.htm
Dias, A. C. G., Patias, N. D., \& Abaid, J. L. W. (2014). Psicologia Escolar e possibilidades na atuação do psicólogo: algumas reflexões. Psicologia Escolar e Educacional, 18(1), 105-111. Recuperado de http:// www.scielo.br/pdf/pee/v18n1/v18n1a1 1.pdf

Facci, M. G. D., \& Silva, S. M. C. (2014). Por uma formação para uma atuação crítica em Psicologia Escolar e Educacional. In M. P. R. Souza, S. M. C. Silva, \& K. Yamamoto (Orgs.), Atuação do Psicólogo na Educação Básica: concepções, práticas e desafios (pp. 275-282). Uberlândia, MG: EDUFU.

Guimarães, M. F. (2014). Depressão, ansiedade, estresse e qualidade de vida de estudantes de universidades pública e privada (Dissertação de mestrado). Programa de Mestrado em Psicologia da Saúde, Universidade Metodista de São Paulo, SP. Recuperado de http://tede.metodista.br/ispui/bitstream/ tede/1348/1/MGuimaraes.pdf

Guzzo, R. S. L. (2001). Saúde Psicológica, Sucesso Escolar e Eficácia na Escola: desafios do novo milênio para a psicologia escolar. In: Z. A. P. Del Prette (Org.), Psicologia Escolar e Educacional: Saúde e Qualidade de Vida (pp.25-42). Campinas, SP: Ed. Alínea.

Instituto Nacional de Estudos e Pesquisas Educacionais Anísio Teixeira. (2014). Matrículas no ensino superior crescem 3,8\%. Brasília: Autor. Recuperado de http://portal.inep.gov.br/artigo/-/asset_publisher/ B4AQV9zFY7Bv/content/matriculas-no-ensinosuperior-crescem-3-8/21206

Lei 10.861, de 14 de abril de 2004. Institui o Sistema Nacional de Avaliação da Educação Superior SINAES e dá outras providências. Recuperado de http://www.planalto.gov.br/ccivil_03/_ato20042006/2004/lei/110.861.htm

Marinho-Araúio, C. M. (2009). Psicologia escolar na educação superior: novos cenários de intervenção e pesquisa. In C. M. Marinho-Araújo (Org.), Psicologia escolar: novos cenários e contextos de pesquisa, formação e prática (pp. 155-202). Campinas, SP: Alínea.

Martínez, A. M. (2009). Psicologia Escolar e Educacional: compromissos com a educação brasileira. Psicologia Escolar e Educacional, 13(1), 169-177. Recuperado de http://www.scielo.br/pdf/pee/v1 3n1/v13n1 a20.pdf. doi: $10.1590 / \mathrm{S} 1413-85572009000100020$

Meira, M. E. M. (2007). Psicologia Histórico-Cultural: Fundamentos, Pressupostos e Articulações com a Psicologia da Educação. In M. E. M. Meira, \& M. G. D. Facci, (Orgs.), Psicologia Histórico-Cultural: contribuições para o encontro entre a subjetividade e a educação (pp. 27-62). São Paulo: Casa do Psicólogo. 
Meira, M. E. M., \& Antunes, M. A. M. (2003). Psicologia escolar: práticas críticas. São Paulo: Casa do Psicólogo.

Mészáros, I. (2006). A Teoria da Alienação em Marx. (I. Tavares, Trad.). São Paulo: Boitempo.

Moura, F. R. (2015). A atuação do psicólogo escolar no Ensino Superior: configurações, desafios e proposições sobre o fracasso escolar (Dissertação de Mestrado). Centro de Ciências Humanas, Letras e Artes, Universidade Estadual de Maringá, Paraná, Brasil. Recuperado de http://www.ppi.uem.br/arquivos-para-links/teses-edissertacoes $/ 2015 /$ fabricio-m

Peres, R. S., Santos, M.A., \& Coelho, H. M. B. (2003). Atendimento psicológico a estudantes universitários: considerações acerca de uma experiência em clínica-escola. Estudos de Psicologia, 20(3), 47 57. Recuperado de http://www.scielo.br/pdf/ estpsi/v20n3/a04.pdf. doi: 10.1590/S0103166X2003000300004

Peres, R. S., Santos, M. A., \& Coelho, H. M. B. (2004). Perfil da clientela de um programa de pronto-atendimento psicológico a estudantes universitários. Psicologia em Estudo, 9(1), 47-54. Recuperado de: http://www. scielo.br/pdf/pe/v9n 1/v9n l a07.pdf. doi: 10.1590/ S1413-73722004000100007

Sampaio, S. M. R. (2010). A psicologia escolar na educação superior: ausências e percalços. Em Aberto, 23(83), 95-105. Recuperado de http://emaberto.inep.gov. $\mathrm{br} /$ index.php/emaberto/article/view/2253. doi: $10.24109 / 2176-6673$.emaberto.23i83.2253

Souza, D. C. (2017). Condições emocionais de estudantes universitários: estresse, depressão, ansiedade, solidão e suporte social (Dissertação de mestrado). Programa de Pós Graduação em Psicologia, Universidade Federal do Triângulo Mineiro, Uberaba, MG, Brasil. Recuperado de http://bdtd.uftm.edu.br/bitstream/ tede/507/5/Dissert\%20Deise\%20C\%20Souza.pdf

Souza, M. P. R. (2010). Psicologia escolar e políticas públicas em educação: desafios contemporâneos. $\mathrm{Em}$ Aberto, 23(83), 129-149. Recuperado de http:// emaberto.inep.gov.br/index.php/emaberto/article/ view $/ 2255 / 2222$ 